\title{
Preparation and Properties Study of Cementitious Grouts Containing Crumb Rubber
}

\author{
Wei Yuan ${ }^{1, *}$, Renfeng Yang ${ }^{1, *}$, Jianyou Yu ${ }^{2}$, Shixin Zhou ${ }^{3}$, Shaoqian Cui ${ }^{2}$, Jian Kang ${ }^{4}$ and Zechen Yao ${ }^{1}$ \\ 1 School of Construction Machinery, Chang'an University, Xi'an 710064, China; 2017025004@chd.edu.cn \\ 2 Yanchong Temporary Preparatory Office of Hebei Province Expressway, Zhangjiakou 075400, China; \\ Y565656yk@163.com (J.Y.); cuishaoqian2021@163.com (S.C.) \\ 3 CSCEC Road and Bridge Group Co., Ltd., Shijiazhuang 050001, China; zhoushixin@cscec.com \\ 4 Highway Administration Bureau of the Department of Transport of Hebei Province, \\ Shijiazhuang 050001, China; kangjian991@126.com \\ * Correspondence: 2018025012@chd.edu.cn (W.Y.); yrfeng@chd.edu.cn (R.Y.)
}

Citation: Yuan, W.; Yang, R.; Yu, J.; Zhou, S.; Cui, S.; Kang, J.; Yao, Z. Preparation and Properties Study of Cementitious Grouts Containing Crumb Rubber. Buildings 2021, 11, 555. https://doi.org/10.3390/ buildings 11110555

Academic Editors: Shengwen Tang and Lei Wang

Received: 21 October 2021

Accepted: 16 November 2021

Published: 18 November 2021

Publisher's Note: MDPI stays neutral with regard to jurisdictional claims in published maps and institutional affiliations.

Copyright: (c) 2021 by the authors. Licensee MDPI, Basel, Switzerland. This article is an open access article distributed under the terms and conditions of the Creative Commons Attribution (CC BY) license (https:/ / creativecommons.org/licenses/by/ $4.0 /)$.

\begin{abstract}
This article aims to improve the toughness of pre-packaged grouts (PPG) by incorporating crumb rubber. The mechanism for toughness of PPG with crumb rubber was analyzed based on the uniaxial compression model. Crumb rubber with surfaces treated by different methods $(\mathrm{NaOH}$ solutions or microwave treatment) was observed by scanning electron microscopy (SEM). The effects of mesh sizes, amounts, surface-treated methods of crumb rubber, and mixing procedures on the PPG's mechanical strength and rheological properties were investigated. The results showed that, firstly, the addition of crumb rubber improves the PPG's toughness, while its mechanical strength is reduced. Adding $\mathrm{NaOH}$ solutions or microwave-treated crumb rubber into PPG can weaken the negative effects of crumb rubber on the PPG's mechanical strength; however, this function is limited. Secondly, the crumb rubber grouts' rheological properties can be fully exploited by increasing the stirring rate and time so that the fluidity of crumb rubber grouts is improved, which fulfils the characteristics of no bleeding and micro-expansion. Finally, the optimal formula and mixing technique of crumb rubber grouts were proposed in this paper.The results of this paper can provide a significant reference for the application of scrap tires.
\end{abstract}

Keywords: crumb rubber; toughness; surface-treated; pre-packaged grouts; influencing mechanisms; preparation methods

\section{Introduction}

Many bridges have been built with post-tensioned (PT), prestressed concrete structures in recent years. PT bridges fulfil the characteristics of high component rigidity, high crack resistance and durability, low self-weight, high crossing ability, and easy assembly [1,2]. In PT bridges, the cementitious grouts are directly in contact with steel strand, which provides a bond between the steel strand and the surrounding concrete for preventing chlorides reaching the steel strands and initiating corrosion [3-5]. As the cementitious grouts are injected after prestressing the steel strand, they are easy to crack due to overloads and vibrations. These cracks may be a direct path for water, chloride, and other corrosioncausing materials to enter the steel strand, causing corrosion. Research has shown that the ductility of PT bridges decreases when the steel strand is exposed to low levels of corrosion. The local rupture of wire can be caused by the severe corrosion of the steel strand $[6,7]$. In other words, the quality of grouts directly impacts the durability, reliability, and safety of PT bridges.

By adding mineral admixtures or chemical additives, researchers can explore grouts that have excellent properties, such as high strength, micro-expansion, no bleeding, and high fluidity. These studies [8-14] investigated the effects of mineral admixtures, such as fly ash, metakaolin, silica fume, slag, rice husk ash, and bauxite, on the fresh and 
hardened properties of grouts. In addition to improving the fluidity of grouts, fly ash permitted grouts to resist segregation and shrinkage [8]. Metakaolin had positive effects on the early-aged and long-term compressive strength of grouts [9]. Grouts that contain silica fume were more workable and stronger in interfacial bonds $[10,15]$. The flowability and chloride resistance of grouts were substantially improved by ground granulated blast furnace slag [11]. Grouts containing bauxite and gypsum had good fluidity and displayed quicksetting, micro-expansion, early strength, and high strength performances [12]. In addition to increasing Marsh cone flow time, plate cohesion, plasticity, apparent viscosity, and yield stress, rice husk ash decreased the mini-slump diameter of grouts [13]. Most studies have focused on the fluidity, bleeding, setting time, and mechanical strength of grouts by adding different chemical additives [2,16-20]. Expansive plastic agents ensured grouts with good fluidity, high strength, and excellent dimensional stability [16]. A superplasticizer reduced the viscosity and yield stress of fresh grouts to assume higher bleeding, longer setting time, and lower compressive strength [17]. Viscosity modifying admixture (VMA) reduced the mini-slump and increased plate cohesion meter, yield stress, and the plastic viscosity of grout, but the increase in VMA dosage reduced their permeability and compressibility at a low water-binder ratio (W/B) and increased them with a higher W/B [18]. The glycolbased, shrinkage-reducing agent might be efficient for improving the cracking resistance of grout [2]. Grouts, however, have a significant surplus of mechanical strength, resulting in increased brittleness. During the hardening process, grouts are susceptible to shrinkage or cracking because of temperature variation or corrosion-mechanical interaction [2,21-24]. Therefore, it is necessary to investigate how to improve the toughness and crack resistance of grout.

Currently, nearly 1.5 billion tires are expected to be withdrawn around the world each year, and the number is sharply increasing [25]. The re-use of scrap tires in construction will contribute to environmentally friendly solutions for scrap tire disposal problems [26]. Makoundou et al. designed an innovative road surface layer by using crumb rubber from scrap tires, which decreases the stiffness of traditional pavement surfaces while helping to improve their durability and reduce the risk of injuries for fallen, vulnerable road users in the urban environment [27]. Alshaikh et al. demonstrated that crumb rubber has resulted in a reduction in the mechanical properties of rubberized concrete mixture compared with normal concrete mixture, while the rubberized concrete frames satisfied the resistance requirements based on comparing their rotational capacities with the guidance in unified facilities criteria and general services administration [28]. Shahrul et al. investigated the mechanical properties of crumb rubber mortar containing nano-silica and the results showed a significant improvement in the mechanical properties of crumb rubber mortar when incorporating nano-silica [26]. Generally, crumb rubber can improve the toughness and crack resistance of concrete without altering its rheological properties [29-32]. Further research needs to be conducted to investigate the preparation and characterization of grouts mixed with crumb rubber. In this study, the crumb rubber grouts were prepared by mixing the crumb rubber with PPG under different mesh sizes, amounts, surface-treated methods, and mixing procedures. Furthermore, this study analyzed the mechanism of toughness of PPG with crumb rubber, and the effect of crumb rubber on the fluidity, bleeding, expansion rate, and mechanical strength of PPG. The optimal formula and mixing technique of crumb rubber grouts were proposed, which are useful for improving the toughness and crack resistance of PPG. In addition, this study provided a way to re-use scrap crumb rubber.

\section{Materials and Methods}

\subsection{Overview of the Experimental Program}

Phase 1: Crumb rubber grouts, in which $0 \%, 2 \%, 4 \%, 6 \%, 8 \%$, and $10 \%$ weight of PPG was replaced by 20,30, 40, and 60 mesh sizes of untreated crumb rubbers, were prepared in this work. The fresh grouts were poured into a mold with a dimension of $40 \mathrm{~mm} \times 40 \mathrm{~mm} \times 160 \mathrm{~mm}$ without vibration and were cured at $20 \pm 2{ }^{\circ} \mathrm{C}$ and $60 \pm 5 \%$ relative humidity for $24 \mathrm{~h}$. After the specimens were removed from the mold, they were 
further cured at $20 \pm 2{ }^{\circ} \mathrm{C}$ and $95 \pm 5 \%$ relative humidity for 3 days, 7 days, and 28 days respectively. The bending strength and compressive strength of the specimens were tested according to Chinese standard GB/T 17671-1999 [33]. In recent years, many researchers have suggested that the bending-compressive strength ratio might be helpful for testing the toughness of cementitious materials. A higher bending-compressive strength ratio could mean a higher toughness [34,35]. Based on the results of compressive strength, bending strength, and the bending-compressive strength ratio, a range of mixing amounts suitable for various mesh sizes of untreated crumb rubber were determined.

Phase 2: Crumb rubber with surfaces treated by $\mathrm{NaOH}$ solutions (NCR) or by microwave (MCR) were mixed with PPG according to the content tested in Phase 1. The specimens were cured for 28 days for compressive strength and bending strength tests. The test results were analyzed and the optimal mixing amount, mesh sizes, and surface-treated method for crumb rubber grouts were determined.

Phase 3: The optimal mixture ratio obtained in Phase 2 was used to prepare crumb rubber grouts at stirring rates ranging from $1600 \mathrm{rpm}$ to $3000 \mathrm{rpm}$ and stirring times varying from $3 \mathrm{~min}$ to $6 \mathrm{~min}$, respectively. Rheological properties such as fluidity, bleeding, and expansion rate were tested according to Chinese standard JTG E30-2005 [36]. The test results were analyzed and an optimum procedure for mixing crumb rubber grouts was developed.

In all these tests, the water-binder ratios were 0.28 and the temperature was $25^{\circ} \mathrm{C}$.

\subsection{Materials}

Commercially available PPG specialized for prestressed duct was manufactured by Hebei Qinghua Building Materials (Shijiazhuang, China) Co., Ltd. for this study. As listed in Table 1, the properties of PPG were evaluated according to JTG/T 3650-2020 [37]. Crumb rubber from the tread layer of truck tires and separated from non-elastomeric components and the 20, 30, 40, and 60 mesh sizes, supplied by Shaanxi Expressway, were used to prepare the crumb rubber grouts. The main technical characteristics of crumb rubber are summarized in Table 2, and the crumb rubber particle size distribution is presented in Table 3.

Table 1. The technical indexes of PPG.

\begin{tabular}{|c|c|c|c|}
\hline \multicolumn{2}{|c|}{ Examination Items } & \multirow{3}{*}{$\begin{array}{c}\text { Measured Value } \\
8.5 \\
10.8 \\
\end{array}$} & \multirow{3}{*}{$\begin{array}{c}\text { Standard Value } \\
\geq 5 \\
\leq 24\end{array}$} \\
\hline Setting time (h) & Initial setting time & & \\
\hline setting time (n) & Final setting time & & \\
\hline \multirow{3}{*}{ Fluidity $\left(25^{\circ} \mathrm{C}\right)(\mathrm{s})$} & Initial fluidity & 16 & $10-17$ \\
\hline & 30 min fluidity & 19 & $10-20$ \\
\hline & 60 min fluidity & 24 & $10-25$ \\
\hline \multirow[b]{2}{*}{ Bleeding rate $(\%)$} & $24 \mathrm{~h}$ free bleeding rate & 0 & 0 \\
\hline & $\begin{array}{l}3 \mathrm{~h} \text { wick-induced } \\
\text { bleeding rate }\end{array}$ & 0 & 0 \\
\hline \multirow{2}{*}{ Pressure bleeding rate (\%) } & $0.22 \mathrm{MPa}$ & 0.7 & \multirow{2}{*}{$\leq 2.0$} \\
\hline & $0.36 \mathrm{MPa}$ & 0.9 & \\
\hline \multirow{2}{*}{ Free expansion rate $(\%)$} & $3 \mathrm{~h}$ & 1.7 & $0-2$ \\
\hline & $24 \mathrm{~h}$ & 2.2 & $0-3$ \\
\hline \multicolumn{2}{|c|}{ Filling degree } & Eligible & Eligible \\
\hline \multirow{3}{*}{ Compressive strength (MPa) } & $3 d$ & 41.6 & $\geq 20$ \\
\hline & $7 \mathrm{~d}$ & 55.2 & $\geq 40$ \\
\hline & $28 \mathrm{~d}$ & 76.2 & $\geq 50$ \\
\hline \multirow{3}{*}{ Bending strength (MPa) } & $3 \mathrm{~d}$ & 9.1 & $\geq 5$ \\
\hline & $7 \mathrm{~d}$ & 11.0 & $\geq 6$ \\
\hline & $28 \mathrm{~d}$ & 12.3 & $\geq 10$ \\
\hline
\end{tabular}


Table 2. The main technical indexes of crumb rubber.

\begin{tabular}{cccccccc}
\hline $\begin{array}{c}\text { Density } \\
\left(\mathbf{g} \cdot \mathrm{cm}^{-3}\right)\end{array}$ & $\begin{array}{c}\text { Water } \\
(\mathbf{\%})\end{array}$ & $\begin{array}{c}\text { Metal } \\
(\mathbf{\%})\end{array}$ & $\begin{array}{c}\text { Fiber } \\
\mathbf{( \% )}\end{array}$ & $\begin{array}{c}\text { Ash } \\
(\mathbf{\%})\end{array}$ & $\begin{array}{c}\text { Acetone } \\
\text { Extractives } \\
\mathbf{( \% )}\end{array}$ & $\begin{array}{c}\text { Carbon } \\
\text { Black (\%) }\end{array}$ & $\begin{array}{c}\text { Rubber } \\
\text { Hydrocarbon } \\
(\%)\end{array}$ \\
\hline 1.17 & 0.75 & 0 & 0.01 & 6.00 & 6.18 & 28 & 61 \\
\hline
\end{tabular}

Table 3. Particle size distribution of crumb rubber.

\begin{tabular}{ccccc}
\hline \multirow{2}{*}{ Sieve Size $(\mathbf{m m})$} & \multicolumn{4}{c}{ Percent Passing (\%) } \\
\cline { 2 - 5 } & $\mathbf{2 0}$ & $\mathbf{3 0}$ & $\mathbf{4 0}$ & $\mathbf{6 0}$ \\
\hline 2.36 & 100 & 100 & 100 & 100 \\
2.00 & 100 & 100 & 100 & 100 \\
1.18 & 99.91 & 100 & 100 & 100 \\
0.6 & 76.01 & 98.91 & 99.95 & 100 \\
0.3 & 31.16 & 43.3 & 42.87 & 99.89 \\
0.15 & 9.9 & 11.40 & 9.97 & 10.10 \\
0.075 & 0.09 & 0.16 & 0.1 & 1.93 \\
\hline
\end{tabular}

\subsection{Crumb Rubber Treated with $\mathrm{NaOH}$ Solutions or Microwave}

The combination of crumb rubber and PPG is poor because crumb rubber is hydrophobic (water-repelling) while PPG is hydrophilic. As a result, the poor interfacial adhesion between these two phases leads to a decrease in strength [38]. The currently available methods for improving the interface strength between crumb rubber and cement-based materials include chemical, thermal, mechanical, thermomechanical, microbial, or irradiation (ultrasound and microwave) methods [39]. For example, $\mathrm{NaOH}$ solutions and microwave treatments have been common approaches for increasing the interface strength between crumb rubber and cement-based materials [39-43]. Therefore, $\mathrm{NaOH}$ solutions and microwave treatment were used to treat the surface of crumb rubber in this study. The step of treating the surfaces involves mixing the crumb rubber into $\mathrm{NaOH}$ solutions with a concentration of $10 \%$. This was mixed with a stirring rate of $1000 \mathrm{rpm}$ for $5 \mathrm{~min}$ to guarantee a uniform treatment of crumb rubber, and then placed in a closed vessel at ambient temperature for $24 \mathrm{~h}$. After the mixture was filtered, the crumb rubber was thoroughly washed with water until its $\mathrm{PH}$ value was $7 \pm 0.1$, and then dried at ambient temperature [40]. During the microwave procedure, the surface of crumb rubber was treated by a microwave oven (Media M1-L213B) with a power of 800 watts. Next, $100 \mathrm{~g}$ of the crumb rubber sample was put into a $250 \mathrm{~mL}$ glass beaker with a stirring rate of $100 \mathrm{rpm}$ for $90 \mathrm{~s}$ [39].

The main instruments used in the test included the SYJ-10 custom-made, high-shear mixer with a maximum rate of $3000 \mathrm{rpm}$ and a bowl capacity of $10 \mathrm{~L}$, the YH-40B constant temperature and humidity curing device for curing specimens, the WE-100B pressure testing machine for bending strength and compressive strength testing. Moreover, a microwave oven was used (Media M1-L213B) for the microwave treatment of crumb rubber, a plexiglass cylinder was used for bleeding at $24 \mathrm{~h}$ with an expansion rate at $3 \mathrm{~h}$ and $24 \mathrm{~h}$, and a plexiglass cylinder with a wick was used for wick-induced bleed at $3 \mathrm{~h}$, along with an inverted cone for initial fluidity, $30 \mathrm{~min}$ fluidity, and $60 \mathrm{~min}$ fluidity testing.

\section{Results and Discussion}

\subsection{Analysis of the Toughening Mechanism of Crumb Rubber on PPG}

Figure 1 shows the bending and compressive failure of PPG mixed with and without crumb rubber. As shown in Figure 1b, d the bending and compressive specimens of the PPG mixed with $6 \%$ crumb rubber were tested and failed to remain without embrittlement cracks after destruction. In fact, the specimens did not change shape, even though their cracks were narrow and interconnected. Although the specimens had cracks, they still had a compressive strength of $15.2 \mathrm{MPa}$ when there was secondary compression failure. 
According to Figure $1 \mathrm{a}, \mathrm{c}$ the bending and compressive specimens of PPG without crumb rubber had the characteristics of brittleness failure. A loud cracking sound was also heard during the test process, and the cracks were extensive and not interconnected. In other words, mixing crumb rubber with PPG was equivalent to adding micro-elastomers, which involves the crack bridging, bending, compressing, and twisting capabilities of crumb rubber into the matrix [44]. In addition, crumb rubber can hinder crack propagation caused by the stress concentration in PPG, delaying the occurrence of new cracks. In summary, crumb rubber grout specimens showed ductile failure characteristics before fracturing compared to PPG specimens. The toughness enhancement of PPG with crumb rubber is advantageous for using this as a recycled material $[45,46]$.

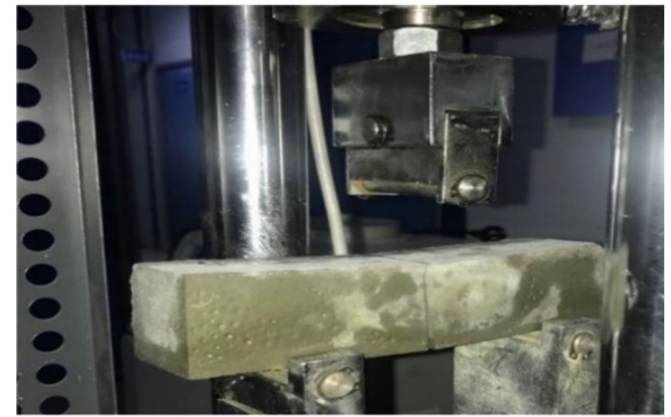

(a) bending failure of PPG without crumb rubber

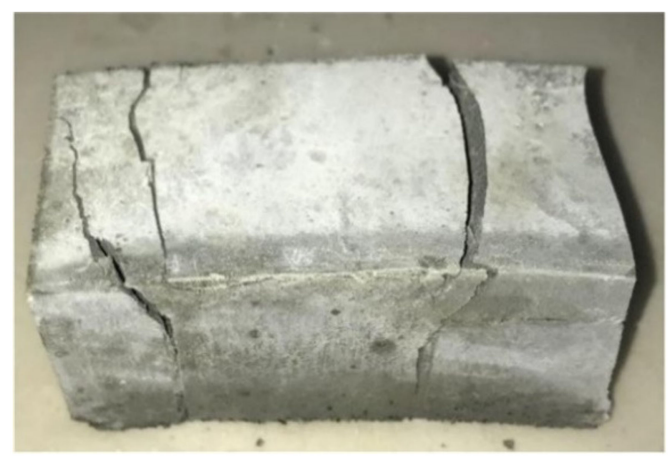

(c) compressive failure of PPG without crumb rubber

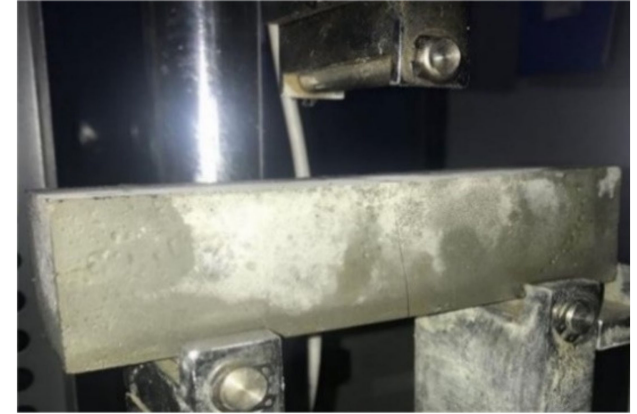

(b) bending failure of PPG with 6\% crumb rubber

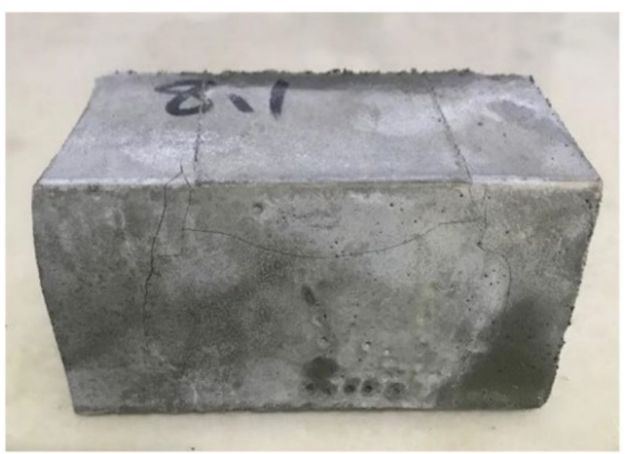

(d) compressive failure of PPG with $6 \%$ crumb rubber

Figure 1. Comparison diagram of the damage of PPG.

The crumb rubber grout's uniaxial compression process was taken as an example for analyzing its toughening mechanism as follows [47]. Based on the assumption that crumb rubber was distributed evenly in PPG, crumb rubber grouts can be described as a two-phase material consisting of a cementitious matrix phase (PPG) and an elastomeric dispersive phase (crumb rubber).

As shown in Figure 2, this paper assumed that only one spherical crumb rubber can be present in a hardened paste in an ideal element.

The average macroscopic strain of crumb rubber grouts under axial pressure is $\varepsilon_{1}$,

$$
\varepsilon_{1}=\varepsilon_{1 a}=\varepsilon_{1 m}
$$

$\varepsilon_{1}$ - The average macroscopic strain of crumb rubber grouts under axial pressure.

$\varepsilon_{1 a}$ - The deformation of crumb rubber.

$\varepsilon_{1 m}$-The deformation of hardened pastes. 


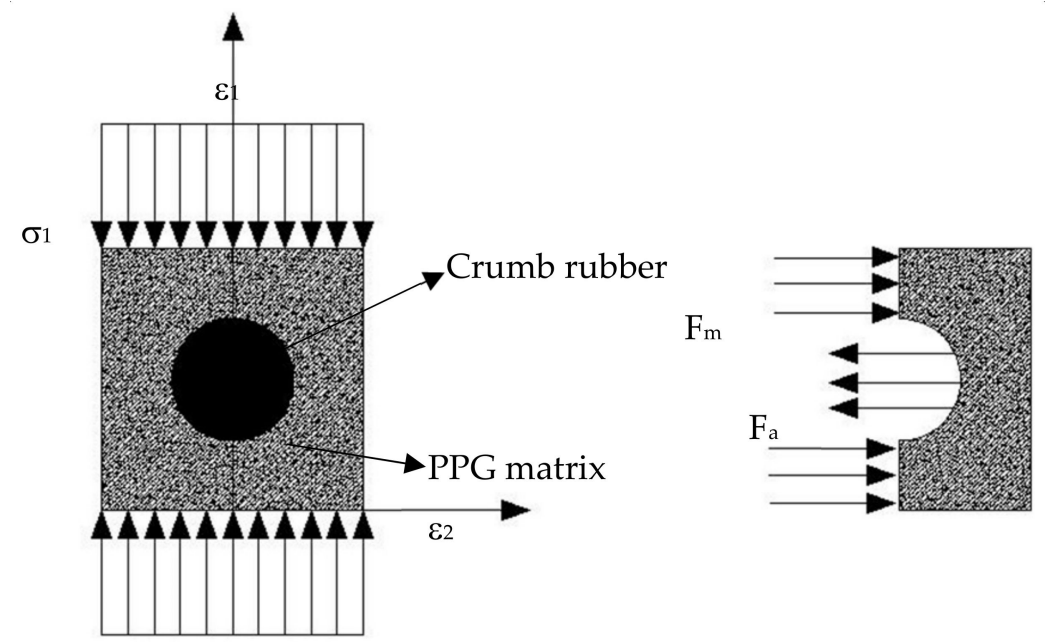

Figure 2. Uniaxial compression schematic diagram of crumb rubber grouts.

In this case, the transverse Poisson free strain calculation without lateral restraint is carried out using Equation (2):

$$
\mathrm{d} \varepsilon_{a}^{p s}=-v_{a} \mathrm{~d} \varepsilon_{1}, \mathrm{~d} \varepsilon_{m}^{p s}=-v_{m} \mathrm{~d} \varepsilon_{1}
$$

$\varepsilon_{a}^{p s}-$ The transverse poisson free strain of crumb rubber.

$\varepsilon_{m}^{p s}$-The transverse poisson free strain of hardened pastes.

$v_{a}$-The poisson ratio of crumb rubber.

$v_{m}$-The poisson ratio of hardened pastes.

The transverse Poisson free strain of crumb rubber is better than hardened pastes because the Poisson ratio of crumb rubber is $0.6-0.8$ and the Poisson ratio of hardened pastes is 0.1-0.18, as shown in Equation (3):

$$
\left|\mathrm{d} \varepsilon_{a}^{p s}\right|>\left|\mathrm{d} \varepsilon_{m}^{p s}\right|
$$

Therefore, the deformation caused by the lateral Poisson's effect on crumb rubber and hardened pastes produces horizontal tensile stress.

It is assumed that there is no shearing slip in the axial compression direction before the crumb rubber grouts crack. From the deformation compatibility conditions, it can be known that:

$$
\mathrm{d} \varepsilon_{a}^{p s}+\mathrm{d} \varepsilon_{a}^{*}=\mathrm{d} \varepsilon_{m}^{p s}+\mathrm{d} \varepsilon_{m}^{*}
$$

$\varepsilon_{a}^{*}$-The transverse constraint strain of crumb rubber.

$\varepsilon_{m}^{*}$-The transverse constraint strain of hardened pastes.

According to the internal force equilibrium condition of two-phase material in the horizontal direction:

$$
\mathrm{d} F_{a}+\mathrm{d} F_{m}=0, \mathrm{~d} F_{a}=A_{a} E_{a} \mathrm{~d} \varepsilon_{a}^{*}, \mathrm{~d} F_{m}=A_{m} E_{m} \mathrm{~d} \varepsilon_{m}^{*}
$$

$F_{a}$-The internal force of crumb rubber in the horizontal direction.

$F_{m}$-The internal force of hardened pastes in the horizontal direction.

$E_{a}$ - The elastic modulus of crumb rubber.

$E_{m}$-The elastic modulus of hardened pastes.

$A_{a}$-The section area of crumb rubber.

$A_{m}$-The section area of hardened pastes.

$$
\mathrm{d} \varepsilon_{m}^{*}=\frac{-A_{a} E_{a} \mathrm{~d} \varepsilon_{a}^{*}}{A_{m} E_{m}}
$$


By substituting Equation (3) into Equation (4), Equation (7) can be obtained:

$$
-v_{a} \mathrm{~d} \varepsilon_{1}+\mathrm{d} \varepsilon_{a}^{*}=-v_{m} \mathrm{~d} \varepsilon_{1}+\mathrm{d} \varepsilon_{m}^{*}
$$

That is:

$$
\mathrm{d} \varepsilon_{a}^{*}=\left(v_{a}-v_{m}\right) \mathrm{d} \varepsilon_{1} /\left(1+\frac{A_{a} E_{a}}{A_{m} E_{m}}\right)
$$

Equation (8) represents the strained relationship between the transverse constraint strain and crumb rubber's axial compression direction before the crumb rubber grouts crack.

It can be seen from Equation (8) that the compressive constraint strain of crumb rubber leads to additional constraint pressure inside the crumb rubber when $v_{a}>v_{m}$, namely Equation (9):

$$
\mathrm{d} \sigma_{a}^{*}=E_{a} \mathrm{~d} \varepsilon_{a}^{*}=\left(v_{a}-v_{m}\right) E_{a} \mathrm{~d} \varepsilon_{1} /\left(1+\frac{A_{a} E_{a}}{A_{m} E_{m}}\right)
$$

$\sigma_{a}^{*}$-The poisson's effect stress of crumb rubber.

The internal stress of crumb rubber at axial pressure $\varepsilon_{1}$ is obtained by Equation (9) with $\varepsilon_{1}$.

$$
\sigma_{a}^{*}\left(\varepsilon_{1}\right)=\left(v_{a}-v_{m}\right) E_{a} \varepsilon_{1} /\left(1+\frac{A_{a} E_{a}}{A_{m} E_{m}}\right)
$$

Similarly, the internal stress of the hardened pastes of PPG grouts is provided by Equation (11):

$$
\sigma_{m}^{*}\left(\varepsilon_{1}\right)=-\left(v_{a}-v_{m}\right) \varepsilon_{1} \frac{A_{a} E_{a}}{A_{m}} /\left(1+\frac{A_{a} E_{a}}{A_{m} E_{m}}\right)
$$

In brief, compressive stress will be generated in the rubber powder, whereas tensile stress will be generated in the hardened pastes of PPG when $v_{a}>v_{m}$. Hence, the crumb rubber takes the place of hardened PPG pastes to bear a portion of the compressive stress before the crumb rubber cracks. At the same time, by increasing axial compression stress, the deformation of the PPG hardened pastes increases due to the excellent deformation ability of the crumb rubber. The interface between the crumb rubber and the cementitious matrix will produce material damage until the crumb rubber grout cracks and fails, which means that the crumb rubber plays a toughening role in the failure process of crumb rubber grouts.

\subsection{Effects of Untreated Crumb Rubber on the Mechanical Strength of PPG}

As can be seen from Figures 3-6:

From the perspective of bending strength, PPG with lower mixing amounts of untreated crumb rubber had a slightly higher bending strength than PPG without untreated crumb rubber. A significant decline in bending strength was observed when PPG was mixed with more than $2 \%$ untreated crumb rubber at different curing periods. At the curing ages of $3 \mathrm{~d}$ or $7 \mathrm{~d}$, the bending strength of the PPG with each untreated crumb rubber dosage was greater than the standard value. At the curing age of $28 \mathrm{~d}$, the PPG incorporating 20 mesh sizes of untreated crumb rubber with 6-10\% dosage showed lower bending strength than the standard value of 0.3-1.7 MPa. The bending strength of PPG incorporating 30 mesh sizes of untreated crumb rubber with $8-10 \%$ dosage was lower than the standard value of 1.1-1.2 MPa. When the mixing amount of 40 or 60 mesh sizes of untreated crumb rubber was $10 \%$, the bending strength of the PPG was less than the standard values of $0.3 \mathrm{MPa}$ or $1.8 \mathrm{MPa}$, respectively. Generally, untreated crumb rubber had a negligible effect on the bending strength of PPG.

The compressive strength of PPG at different curing periods showed a downtrend when the crumb rubber dosages were increased. When the curing age was $3 \mathrm{~d}$, the compressive strength of PPG incorporating 40 mesh sizes of untreated crumb rubber with $10 \%$ dosage was only lower than the standard value of $0.7 \mathrm{MPa}$, while the compressive strength of PPG with other mesh sizes of untreated crumb rubber with $0-10 \%$ dosage was higher 
than $20 \mathrm{MPa}$. When the curing age was $7 \mathrm{~d}$, the compressive strength of PPG was less than $40 \mathrm{MPa}$ and the mixing amount of 20 or 30 mesh sizes of untreated crumb rubber was greater than $6 \%$. Nevertheless, the compressive strength of PPG was greater than $40 \mathrm{MPa}$ when the mixing amount of 40 or 60 mesh sizes of untreated crumb rubber was $6 \%$. The compressive strength of PPG was less than $40 \mathrm{MPa}$ when the mixing amount of 40 or 60 mesh sizes of untreated crumb rubber was more significant than $6 \%$. When the curing age was $28 \mathrm{~d}$, the compressive strength of PPG incorporating 20 mesh sizes of untreated crumb rubber with $6 \%$ dosage was lower than $50 \mathrm{MPa}$; the compressive strength of PPG containing other mesh sizes of untreated crumb rubber with 0-6\% dosage was higher than $50 \mathrm{MPa}$, and with $8-10 \%$ dosage it was lower than $50 \mathrm{MPa}$.

The bending-compressive strength ratio of PPG at different curing periods showed an increase in tendency along with the increase in the mixing amount of untreated crumb rubber, which was significantly higher than that of the PPG without untreated crumb rubber. With the dosage of untreated crumb rubber exceeding $8 \%$, however, the bendingcompressive strength ratio of the PPG mixed with 20 or 60 mesh sizes of crumb rubber showed a downward trend. On the other hand, the bending-compressive strength ratio of PPG mixed with 30 or 40 mesh sizes of crumb rubber showed an upward trend. This would seem to indicate that too large or too small a diameter of crumb rubber negatively affects the PPG's bending-compressive strength ratio. As the curing age increases, the bendingcompressive strength ratio of PPG mixed with untreated crumb rubber decreases.

Judging from the compressive strength, bending strength, and the bending-compressive strength ratio of PPG mixed with untreated crumb rubber, the optimal dosage of 20 or 30 mesh sizes of untreated crumb rubber in PPG was $4 \%$. The optimal dosage of 40 or 60 mesh sizes of untreated crumb rubber in PPG was 6\%.

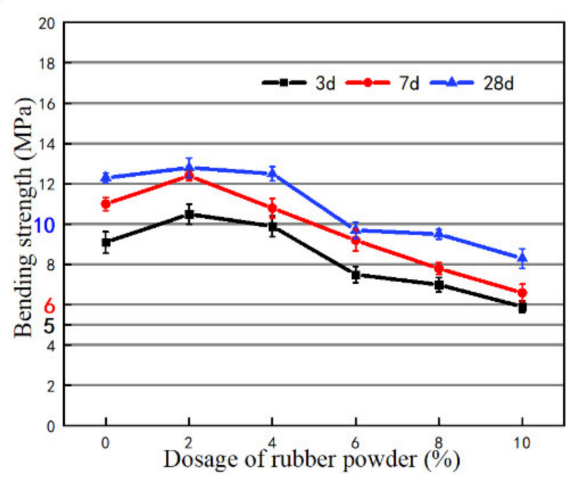

(a) bending strength

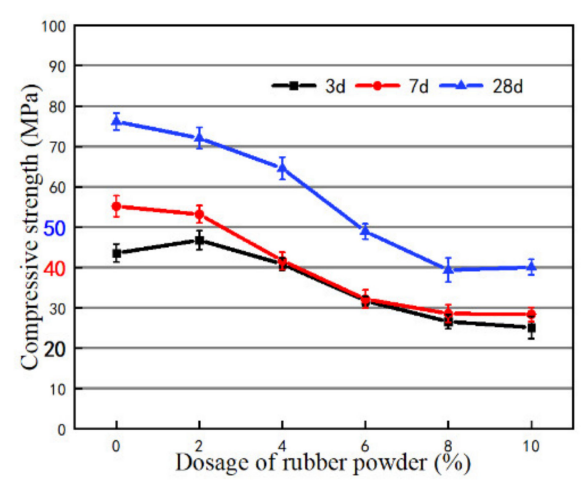

(b) compressive strength

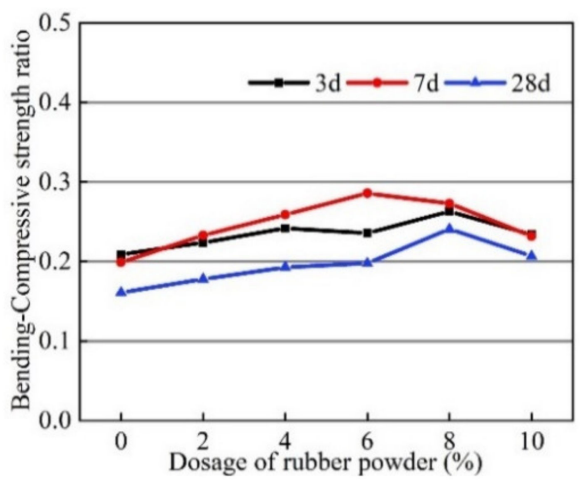

(c) bending-compressive strength ratio

Figure 3. Mechanical strength of PPG with untreated 20 mesh of crumb rubber at different dosages.

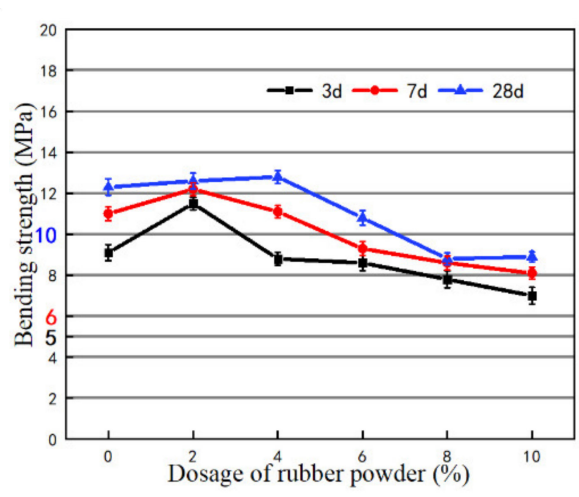

(a) bending strength

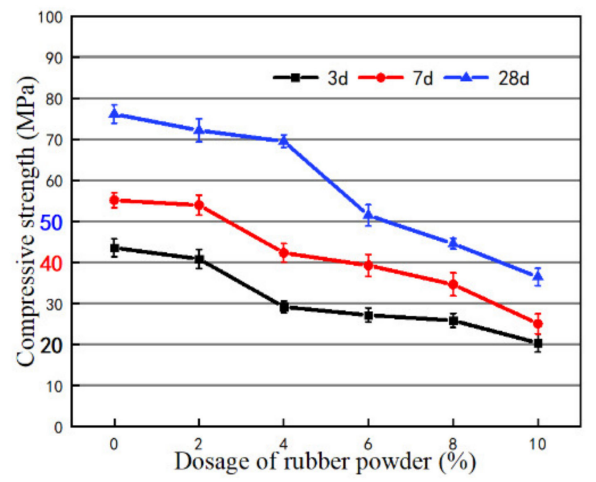

(b) compressive strength

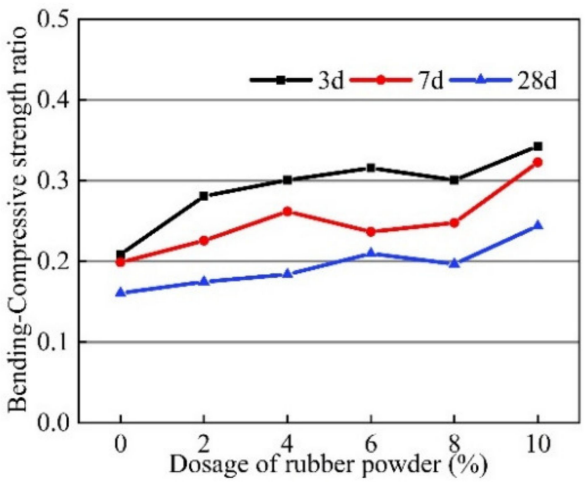

(c) bending-compressive strength ratio

Figure 4. Mechanical strength of PPG with untreated 30 mesh of crumb rubber at different dosages. 


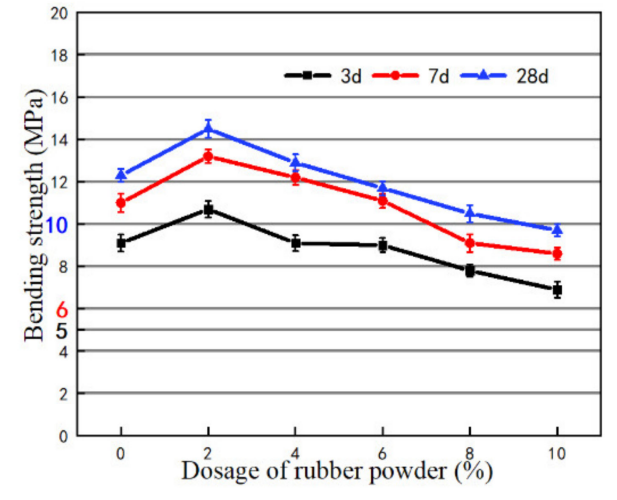

(a) bending strength

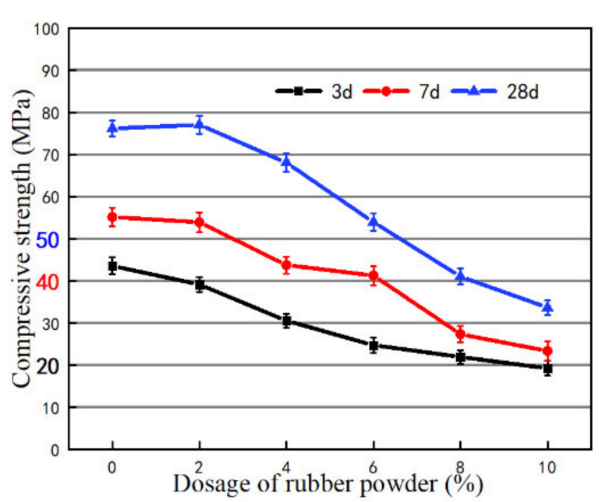

(b) compressive strength

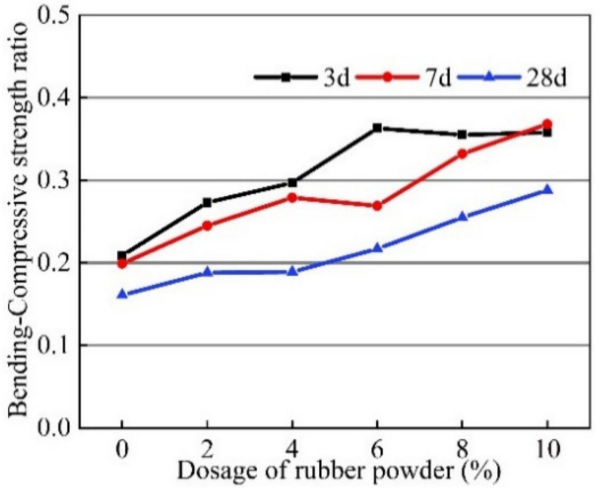

(c) bending-compressive strength ratio

Figure 5. Mechanical strength of PPG with untreated 40 mesh of crumb rubber at different dosages.

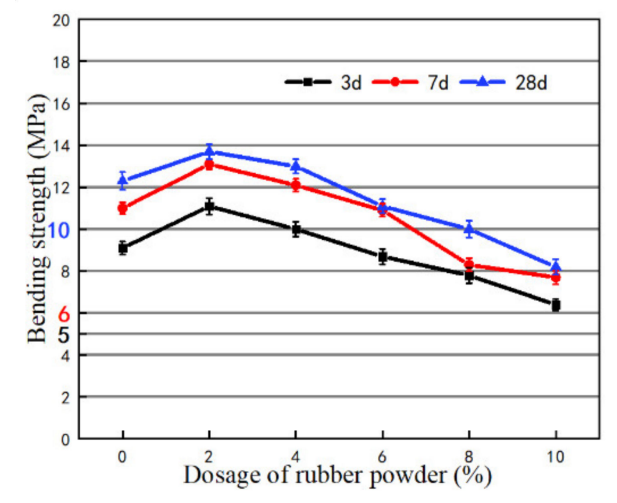

(a) bending strength

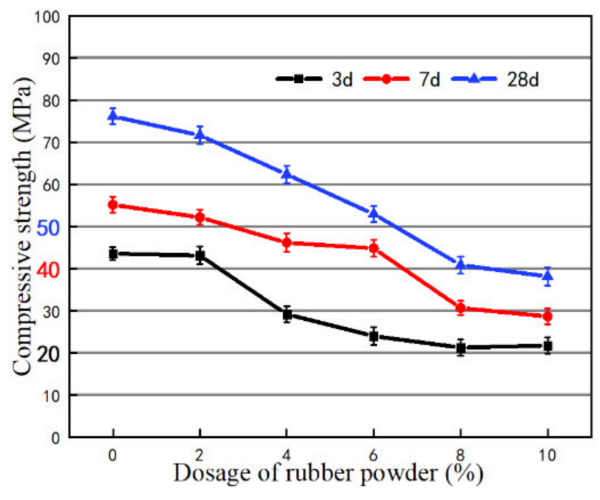

(b) compressive strength

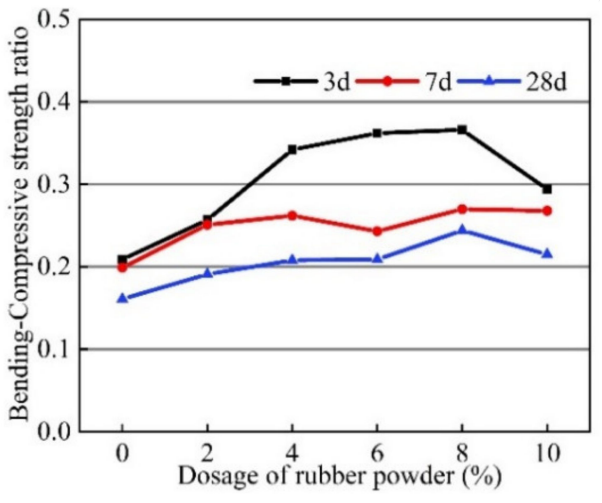

(c) bending-compressive strength ratio

Figure 6. Mechanical strength of PPG with untreated 60 mesh of crumb rubber at different dosages.

\subsection{Effects of NCR and MCR on the Mechanical Strength of PPG}

In the results discussed in Section 3.2, it should be noted that the compressive strength and bending strength of the PPG that incorporated 20 or 30 mesh sizes of untreated crumb rubber with $6 \%$ dosage were slightly lower than the standard value. For example, the compressive strength of the PPG containing 30 mesh sizes of untreated crumb rubber with $6 \%$ dosage was only lower than the standard value of $0.7 \mathrm{MPa}$ when the curing age was $7 \mathrm{~d}$. However, the bending-compressive strength ratio of PPG increased by $9.3 \%$ compared with that of $4 \%$ untreated crumb rubber. Therefore, in order to improve the dosage of crumb rubber in the PPG, this section investigates the influence of crumb rubber with different surface-treated methods $(\mathrm{NaOH}$ solutions or microwave treatment) on the mechanical properties of PPG.

As evident from Figure 7, adding surface-treated crumb rubber into PPG can effectively improve the mechanical strength and toughness of PPG. PPG mixed with 20 mesh sizes of untreated crumb rubber, for example, had compressive and bending strengths lower than the standard values of $1.03 \mathrm{MPa}$ and $0.3 \mathrm{MPa}$. On the contrary, the compressive strength of PPG mixed with 20 mesh sizes for NCR or MCR increased by $28.24 \%$ and $12.31 \%$, respectively, and the bending strength increased by $26.80 \%$ and $23.71 \%$, respectively, which is higher than the standard values. Simultaneously, the bending-compressive strength ratio of PPG mixed with NCR or MCR decreased by $1.12 \%$ and increased by $10.15 \%$, respectively. This comparison showed that PPG incorporated with surface-treated crumb rubber can weaken the negative effects of the crumb rubber on the mechanical strength of PPG while maintaining its good toughness. 
The mechanical strength and toughness of PPG were slightly improved by the surfacetreated crumb rubber. From the calculation of the data in Figure 7, it can be obtained that the compressive strength of the PPG mixed with NCR or MCR compared with that of untreated crumb rubber varied from -3.41 to $28.24 \%$ and -9.31 to $12.31 \%$, respectively, the bending strength varied from 3.85 to $26.80 \%$ and -6.30 to $23.71 \%$, respectively, and the ratio of bending-compressive strength varied from -2.85 to $12.49 \%$ and -1.85 to $10.85 \%$, respectively.

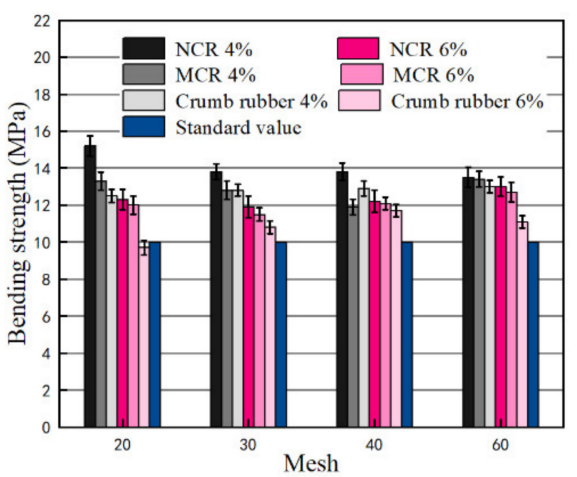

(a) bending strength

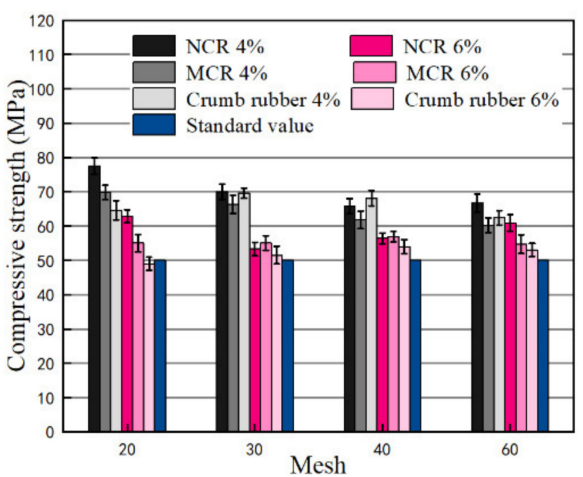

(b) compressive strength

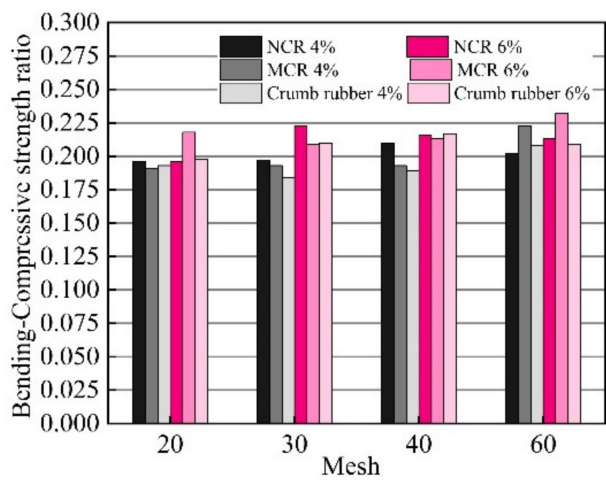

(c) bending-compressive strength ratio

Figure 7. Mechanical strength of PPG at $28 \mathrm{~d}$ curing age with surface-treated crumb rubber.

The main reason for the above results is that zinc stearate $\left(\mathrm{Z}_{n}\left(\mathrm{C}_{17} \mathrm{H}_{35} \mathrm{CO0}\right)_{2}\right)$ on the surface of crumb rubber causes poor adhesion characteristics and creates a barrier layer between the crumb rubber and PPG. With the $\mathrm{NaOH}$ solution treatment, zinc stearate turns into sodium stearate $\left(\mathrm{C}_{17} \mathrm{H}_{35} \mathrm{C} 00 \mathrm{Na}\right)$, which is water-soluble. The sodium stearate $\left(\mathrm{C}_{17} \mathrm{H}_{35} \mathrm{COONa}\right)$ can be easily removed from the crumb rubber surfaces by adequately washing them after treatment, thus improving the bonding ability between crumb rubber and PPG $[40,48,49]$. Additionally, the chemical structure of crumb rubber can be modified by microwave radiation, mainly destroying $C-S$ and $S-S$ bonds but not altering $C=C$ bonds, forming a surface of crumb rubber with lower insoluble portions [39,50]. With microwave devulcanization, a large amount of energy is applied rapidly and uniformly, breaking cross-links of sulfur in crumb rubber without using chemical reagents during the process, which is an eco-friendly and efficient method. Micrographs of untreated crumb rubber, NCR, and MCR were taken using a scanning electron microscope (SEM).

Figure 8 shows that, compared with untreated crumb rubber, the crumb rubber which was treated by $\mathrm{NaOH}$ solutions or microwave treatment created a flocculent structure on the surface of crumb rubber that was similar to the swelling of crumb rubber. In addition, treated by either $\mathrm{NaOH}$ solutions or microwave treatment, crumb rubber could provide a rougher surface, which helped the combination of crumb rubber and PPG. It could reduce the loss of the mechanical strength of PPG.

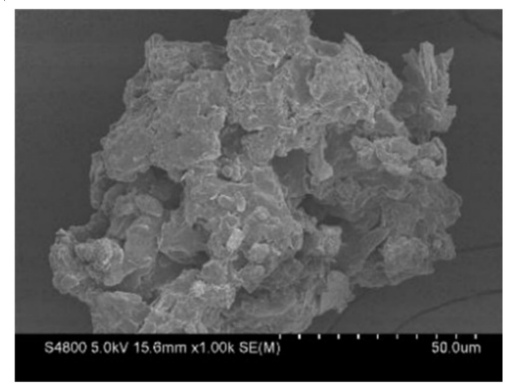

(a) untreated crumb rubber

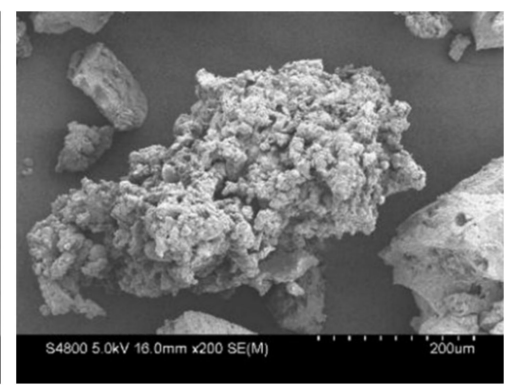

(b) NCR

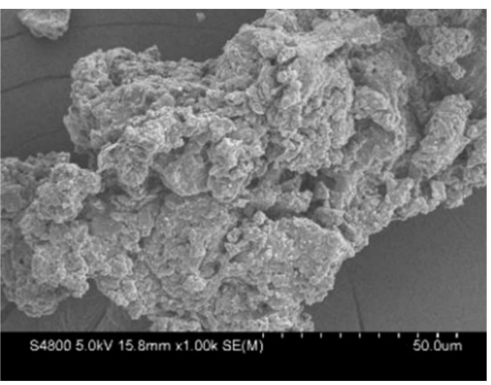

(c) MCR

Figure 8. SEM micrographs of untreated crumb rubber, NCR, and MCR. 
In summary, the optimal mixing amount, particle size, and surface-treatment method of crumb rubber was 6\%, 60 mesh, and microwave treatment, respectively. Under this mixture ratio, when compared with that of the PPG without crumb rubber, the compressive strength and bending strength of PPG with crumb rubber decreased by $28.2 \%$ and 3.2\%, respectively, but the toughness increased by $44.1 \%$ after curing for 28 days.

\subsection{Effects of Stirring Rate and Stirring Time on the Rheological Properties of Crumb Rubber Grouts}

This section aims to analyze the effect of the mixing procedure on the rheological properties of crumb rubber grouts. The optimal mixture ratio proposed in Section 3.3 was used to prepare crumb rubber grouts at the stirring rate ranging from $1600 \mathrm{rpm}$ to $3000 \mathrm{rpm}$ and stirring time ranging from $3 \mathrm{~min}$ to $6 \mathrm{~min}$. The rheological properties of crumb rubber grouts were immediately tested after the preparation of crumb rubber grouts, including fluidity, bleeding rate, and expansion rate.

\subsubsection{Effects of Stirring Rate and Stirring Time on the Fluidity of Crumb Rubber Grouts}

In Figure 9, the fluidity of crumb rubber grouts was generally improved with the increase in stirring rate while at the same stirring time. The fluidity of the crumb rubber grouts increased rapidly when the stirring rate was altered from $1600 \mathrm{rpm}$ to $2000 \mathrm{rpm}$. Then, the fluidity of crumb rubber grouts increased slowly as the stirring rate was gradually increased. Comparing the fluidity results in Figure 9 with Table 2, it is shown that crumb rubber grouts have slightly higher fluidity than PPG. The results of the fluidity of crumb rubber grouts could be interpreted as that the sheer force of the mixer blade on the crumb rubber grouts was enhanced with the increase in stirring rate. As a result, the structure of each crumb rubber grout component was destroyed, the force between particles was reduced, and the slurry was more uniform. Due to the increase in stirring rate and stirring time, the chemical reaction between each element of crumb rubber grout was accelerated, resulting in a release of more free water in crumb rubber grouts and an increase in fluidity. However, with the increase in the stirring rate, the degree of mixing uniformity, chemical reaction, and interparticle force among all components in the crumb rubber grouts reached the maximum. Then, the fluidity of crumb rubber grouts did not change with the increase in the stirring rate and stirring time. Further, due to the spherical shape of crumb rubber playing a roller role in crumb rubber grouts, the dispersion of crumb rubber could increase the fluidity of slurry.

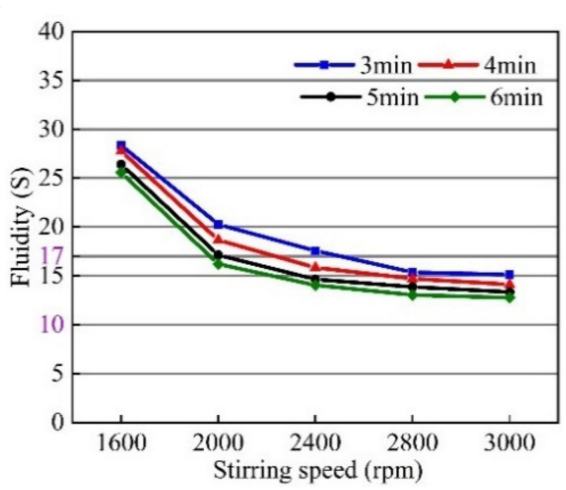

(a) initial fluidity

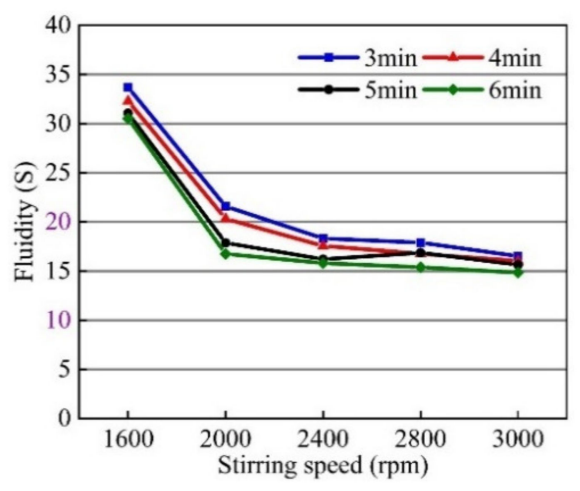

(b) 30 min fluidity

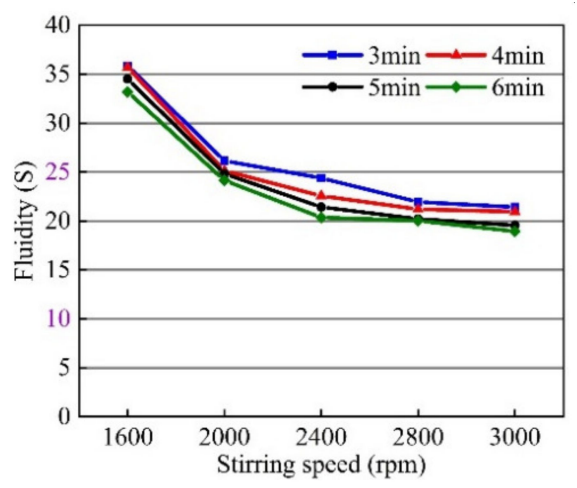

(c) 60 min fluidity

Figure 9. The fluidity of crumb rubber grouts under different stirring rates and stirring times.

3.4.2. Effects of Stirring Rate and Stirring Time on the Bleeding Rate and Expansion Rate of Crumb Rubber Grouts

Figure 10 shows the bleeding rate and free expansion rate testing of crumb rubber grouts. The bleeding experimental data of crumb rubber grouts suggested that only when 
the stirring rate was $1600 \mathrm{rpm}$ and the stirring time was $3 \mathrm{~min}$, the $3 \mathrm{~h}$ wick-induced bleeding rate was $0.2 \%$ and the $24 \mathrm{~h}$ free bleeding rate was 0 . The reason for this could be that crumb rubber grouts produce a small amount of bleeding under the lower stirring rates and stirring times, but the bleeding can be completely absorbed by crumb rubber grouts during the hardening process within $24 \mathrm{~h}$. If the stirring rate and stirring time exceed a specific point ( $2000 \mathrm{rpm}, 3 \mathrm{~min}$ ), there will be no bleeding when mixing crumb rubber with $6 \%$ dosage in the PPG.
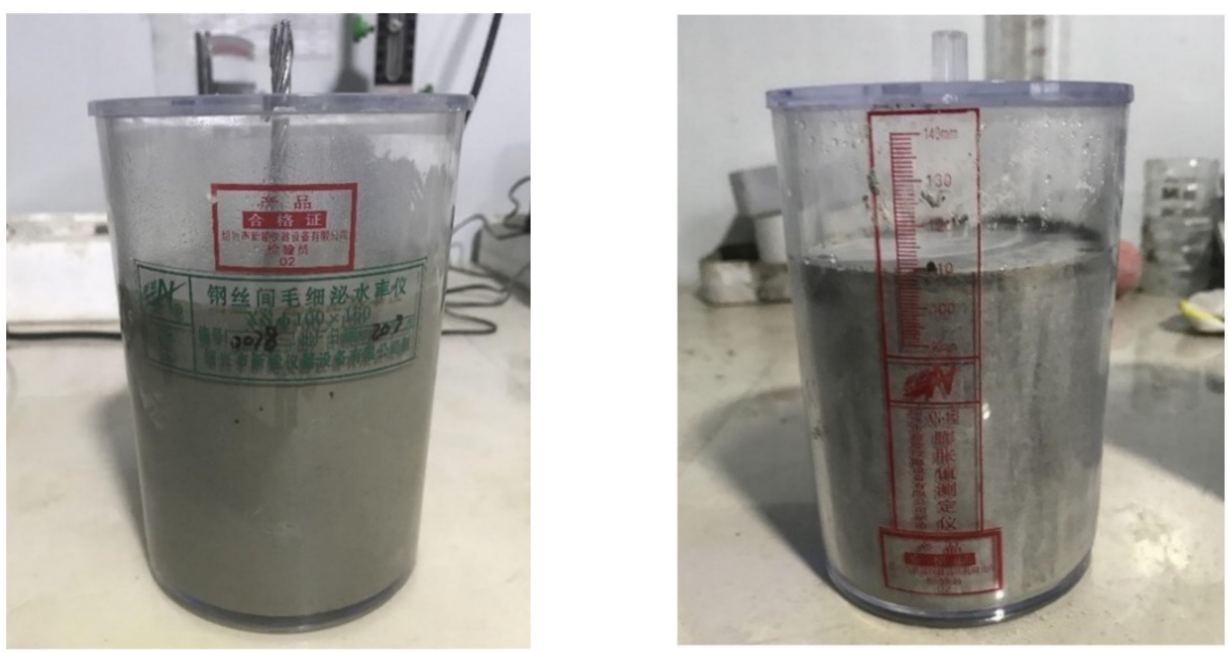

Figure 10. Bleeding rate and free expansion rate testing of crumb rubber grouts.

In addition, Figure 11 shows that the crumb rubber was evenly distributed in the hardened slurry without crumb rubber segregation and a soft slurry layer. In this case, one possible reason might be that the crumb rubber was well distributed in the PPG after mixing, and that the crumb rubber grouts have a viscosity of $1.4 \mathrm{~Pa} \cdot \mathrm{s}$ after mixing. Moreover, the crumb rubber wrapped within the slurry inhibits crumb rubber separation. As time goes by, the crumb rubber grout slurry gradually solidifies from the solid-liquid two-phase state, and the resistance to crumb rubber segregation in the slurry also increases.

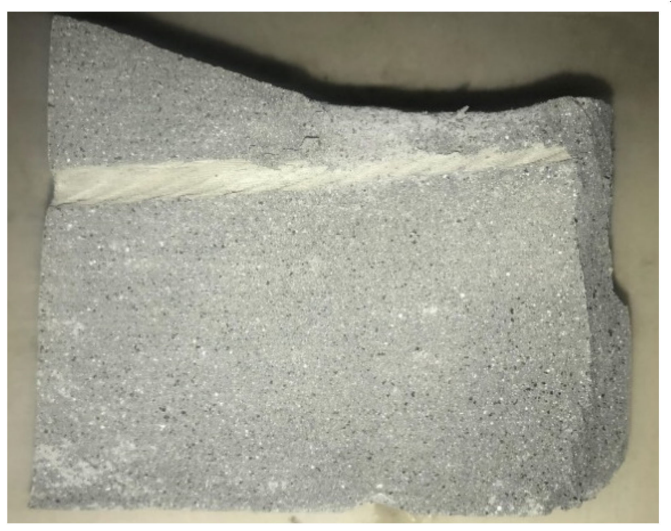

Figure 11. Section diagram of hardened paste of crumb rubber grouts.

Figure 12 shows the expansion rate experimental data of crumb rubber grouts. As shown in Figure 12, the $3 \mathrm{~h}$ and $24 \mathrm{~h}$ free expansion rates of crumb rubber grouts were smaller when the stirring rate was less than $2000 \mathrm{rpm}$ and the stirring time was less than $4 \mathrm{~min}$. By increasing the stirring rate or stirring time, the $3 \mathrm{~h}$ and $24 \mathrm{~h}$ free expansion rates can be effectively increased. The stirring time had a slight effect on the $3 \mathrm{~h}$ and $24 \mathrm{~h}$ free expansion rates of crumb rubber grouts when the stirring rate reached $2800 \mathrm{rpm}$. In other words, the expansion performance of the crumb rubber grouts can only be fully utilized at 
a certain level of stirring rate and stirring time. Moreover, the $3 \mathrm{~h}$ and $24 \mathrm{~h}$ free expansion rates of crumb rubber grouts were lower than the PPG without crumb rubber, as shown in Table 2. In fact, the reason for this is that crumb rubber has good elasticity, therefore, the expansion stress that exists in crumb rubber grouts can be eliminated by crumb rubber if crumb rubber is evenly dispersed in PPG.

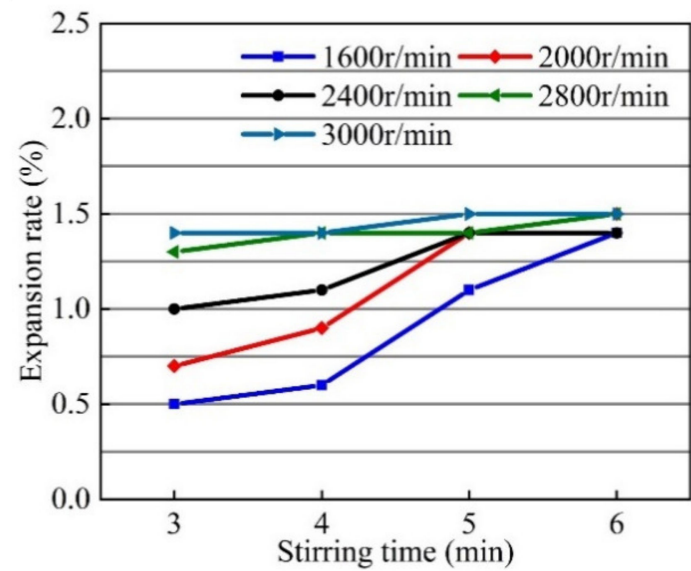

(a) $3 \mathrm{~h}$ free expansion

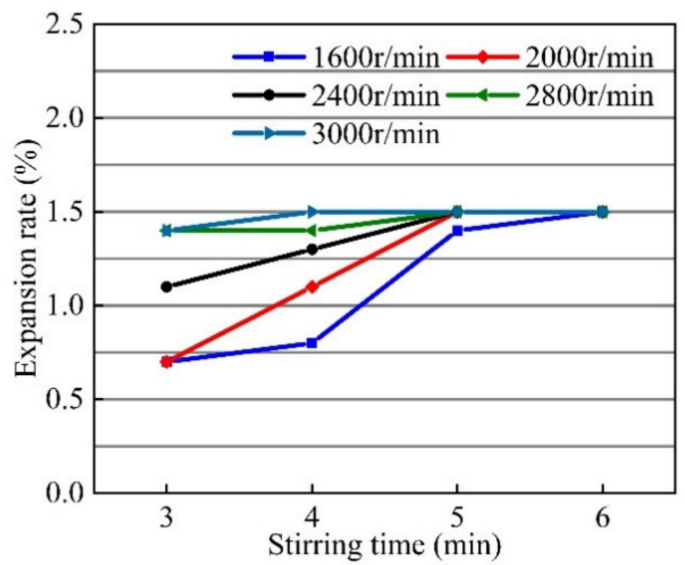

(b) $24 \mathrm{~h}$ free expansion

Figure 12. The expansion rates of crumb rubber grouts under different stirring rates and stirring times.

In summary, this paper suggests that the stirring rate and the stirring time of crumb rubber grouts was $2800 \mathrm{rpm}$ and $4 \mathrm{~min}$, respectively. In this case, the rheological properties of crumb rubber grouts can be fully exerted, and the crumb rubber grouts exhibit no bleeding and micro-expansion characteristics. Compared with that of the PPG without crumb rubber, the initial fluidity, $30 \mathrm{~min}$ fluidity, and $60 \mathrm{~min}$ fluidity of PPG with the optimal mixture ratio of rubber powder were increased by $8.1 \%, 11.8 \%$, and $11.6 \%$, respectively, while the $3 \mathrm{~h}$ free expansion rate and $24 \mathrm{~h}$ free expansion rate were decreased by $17.6 \%$ and $36.4 \%$, respectively, after curing for $28 \mathrm{~d}$.

\section{Conclusions}

In this study, an optimal mixture ratio and mixing procedure were proposed for adding crumb rubber into commercially available PPG. This study described the toughening mechanism, mechanical properties, and rheological properties of crumb rubber grouts under different mesh sizes, dosages, surface-treated methods, and mixing procedures. A series of experiments, including bending strength, compressive strength, fluidity, bleeding rate, and expansion rate were performed. The following conclusions can be drawn from the experimental results:

(1) Compared to the PPG without crumb rubber, the compressive strength and bending strength of PPG with crumb rubber decreased as the percentage of crumb rubber increased, but an increase in toughness of crumb rubber grouts was also observed.

(2) The zinc stearate on the surface of crumb rubber causes poor adhesion properties and creates a barrier layer between the crumb rubber and PPG. Thus, adding untreated rubber powder into PPG greatly reduces its compressive strength. However, $\mathrm{NaOH}$ solutions or microwave-treated crumb rubber can weaken the negative effects of the crumb rubber on the mechanical strength of PPG while improving its good toughness.

(3) This paper suggested that the optimal mixing amount, mesh sizes, and surface-treated method of crumb rubber in PPG was 6\%, 60 mesh, and microwave-treated, respectively. Under this mixture ratio, compared to the PPG without crumb rubber, the compressive strength and bending strength of PPG with crumb rubber decreased by $28.2 \%$ and $3.2 \%$, respectively, but the toughness increased by $44.1 \%$ after curing for 28 days.

(4) By increasing the stirring rate and the stirring time, the rheological properties of crumb rubber grouts can be fully exerted, and the crumb rubber grouts exhibit no bleeding 
and micro-expansion characteristics. This paper suggested that the stirring rate and the stirring time of crumb rubber grouts was $2800 \mathrm{rpm}$ and $4 \mathrm{~min}$, respectively.

(5) The mechanical strength, toughness, and rheological properties of crumb rubber grouts proposed in this paper can meet engineering needs and can aid the quick digestion of scrap crumb rubber, which has significant environmental, economic, and engineering significance. For future work, it is necessary to further study the stress-strain relationship of crumb rubber grouts and how to increase the amount of crumb rubber in cementitious grouts.

Author Contributions: Conceptualization, W.Y.; methodology, W.Y., R.Y. and Z.Y.; software, W.Y.; validation, R.Y. and J.Y.; formal analysis, W.Y.; investigation, W.Y. and R.Y.; resources, J.Y.; data curation, W.Y.; writing—original draft preparation, W.Y.; writing—review and editing, R.Y., J.Y., S.Z., S.C., J.K. and Z.Y.; visualization, W.Y.; supervision, R.Y., J.Y. and S.Z.; project administration, J.Y. and S.C.; funding acquisition, J.Y. All authors have read and agreed to the published version of the manuscript.

Funding: This research was funded by the Science and Technology Research Project of Hebei Provincial Transport Department of China, grant number YC-201922.

Institutional Review Board Statement: Not applicable.

Informed Consent Statement: Not applicable.

Data Availability Statement: The data used to support the findings of this study are available from the corresponding author upon request.

Conflicts of Interest: The authors declare no conflict of interest.

\section{References}

1. Cheng, X.S.; Liu, H.B.; Su, J.X.; Ma, L.; Li, G.L. Flexural Performance of Prestressed Beams with Grouting Material of Various Compactnesses. KSCE J. Civ. Eng. 2020, 24, 2419-2434. [CrossRef]

2. Yoo, D.Y.; Ryu, G.S.; Yuan, T.F.; Koh, K.T. Mitigating shrinkage cracking in posttensioning grout using shrinkage-reducing admixture. Cem. Concr. Compos. 2017, 81, 97-108. [CrossRef]

3. Kamalakannan, S.; Thirunavukkarasu, R.; Pillai, R.G.; Santhanam, M. Factors affecting the performance characteristics of cementitious grouts for post-tensioning applications. Constr. Build. Mater. 2018, 180, 681-691. [CrossRef]

4. Gopinathan, S.; Anand, K.B. Properties of cement grout modified with ultra-fine slag. Front. Struct. Civ. Eng. 2017, 12, 58-66. [CrossRef]

5. Wang, L.; Lu, X.; Li, X. Influence of reactivity and dosage of $\mathrm{MgO}$ expansive agent on shrinkage and crack resistance of face slab concrete. Cem. Concr. Compos. 2021, 104333. [CrossRef]

6. Jeon, C.H.; Shim, C.S. Flexural Behavior of Post-Tensioned Concrete Beams with Multiple Internal Corroded Strands. Appl. Sci. 2020, 10, 7994. [CrossRef]

7. Rinaldi, Z.; Imperatore, S.; Valente, C. Experimental evaluation of the flexural behavior of corroded P/C beams. Constr. Build. Mater. 2010, 24, 2267-2278. [CrossRef]

8. Mohan, M.K.; Pillai, R.G.; Santhanam, M.; Gettu, R. High-performance cementitious grout with fly ash for corrosion protection of post-tensioned concrete structures. Constr. Build. Mater. 2021, 281, 122612. [CrossRef]

9. Vavričuk, A.; Bokan-Bosiljkov, V.; Kramar, S. The influence of metakaolin on the properties of natural hydraulic lime-based grouts for historic masonry repair. Constr. Build. Mater. 2018, 172, 706-716. [CrossRef]

10. Xu, S.Q.; Ma, Q.L.; Wang, J.L.; Wang, L.L. Grouting performance improvement for natural hydraulic lime-based groutvia incorporating silica fume and silicon-acrylic latex. Constr. Build. Mater. 2018, 186, 652-659. [CrossRef]

11. Kim, D.J.; Park, G.J.; Le, H.V.; Moon, D.Y. Fresh and hardened properties of steel fiber-reinforced grouts containing ground granulated blast-furnace slag. Constr. Build. Mater. 2016, 122, 332-342. [CrossRef]

12. Ma, C.; Tan, Y.H.; Li, E.B.; Dai, Y.S.; Yang, M. High-Performance Grouting Mortar Based on Mineral Admixtures. Adv. Mater. Sci. Eng. 2015, 2015, 425456. [CrossRef]

13. Celik, F.; Canakci, H. An investigation of rheological properties of cement-based grout mixed with rice husk ash (RHA). Constr. Build. Mater. 2015, 91, 187-194. [CrossRef]

14. Wang, L.; Guo, F.X.; Lin, Y.Q. Comparison between the effects of phosphorous slag and fly ash on the C-S-H structure, long-term hydration heat and volume deformation of cement-based materials. Constr. Build. Mater. 2020, 250, 118807. [CrossRef]

15. Wang, L.; Jin, M.M.; Guo, F.X. Pore structural and fractal analysis of the influence of fly ash and silica fume on the mechanical property and abrasion resistance of concrete. Fractals 2021, 29, 2140003. [CrossRef]

16. Zhang, G.F; Qiu, D.W.; Wang, S.X.; Wang, P.M. Effects of plastic expansive agent on the fluidity, mechanical strength, dimensional stability and hydration of high performance cementitious grouts. Constr. Build. Mater. 2020, 243, 118204. [CrossRef] 
17. Zhang, S.; Qiao, W.G.; Chen, P.C.; Xi, K. Rheological and mechanical properties of microfine-cement-based grouts mixed with microfine fly ash, colloidal nanosilica and superplasticizer. Constr. Build. Mater. 2019, 212, 10-18. [CrossRef]

18. Sonebi, M.; Perrot, A. Effect of mix proportions on rheology and permeability of cement grouts containing viscosity modifying admixture. Constr. Build. Mater. 2019, 212, 687-697. [CrossRef]

19. Wang, L.; Guo, F.X.; Yang, H.M. Comparison of Fly Ash, Pva Fiber, Mgo and Shrinkage-Reducing Admixture on the Frost Resistance of Face Slab Concrete Via Pore Structural and Fractal Analysis. Fractals 2021, 29, 2140002. [CrossRef]

20. Huang, J.S.; Li, W.W.; Huang, D.S. Fractal Analysis on Pore Structure and Hydration of Magnesium Oxysulfate Cements by First Principle, Thermodynamic and Microstructure-Based Methods. Fractal Fract. 2021, 5, 164. [CrossRef]

21. Breen, J.E. Techniques for Improving Durability of Post-Tensioned Concrete Bridges. Arab. J. Sci. Eng. 2012, 37, 303-314. [CrossRef]

22. Kataria, S. Assessment of Grouts for Constructability and Durability of Post-Tensioned Bridges. Master's Thesis, Texas A\&M University, College Station, TX, USA, 2008.

23. Anania, L.; Badalà, A.; D'Agata, G. Damage and collapse mode of existing post tensioned precast concrete bridge: The case of Petrulla viaduct. Eng. Struct. 2018, 162, 226-244. [CrossRef]

24. Wang, L.; Luo, R.Y.; Zhang, W. Effects of Fineness and Content of Phosphorus Slag on Cement Hydration, Permeability, Pore Structure and Fractal Dimension of Concrete. Fractals 2021, 29, 2140004. [CrossRef]

25. Alwesabi, E.A.H.; Bakar, B.H.A.; Alshaikh, I.M.H.; Zeyad, A.M.; Altheeb, A.; Alghamdi, H. Experimental investigation on fracture characteristics of plain and rubberized concrete containing hybrid steel-polypropylene fiber. Structures 2021, 33, 4421-4432. [CrossRef]

26. Shahrul, S.; Mohammed, B.S.; Wahab, M.M.A.; Liew, M.S. Mechanical Properties of Crumb Rubber Mortar Containing Nano-Silica Using Response Surface Methodology. Materials 2021, 14, 5496. [CrossRef]

27. Makoundou, C.; Sangiorgi, C.; Johansson, K.; Wallqvist, V. Development of Functional Rubber-Based Impact-Absorbing Pavements for Cyclist and Pedestrian Injury Reduction. Sustainability 2021, 13, 11283. [CrossRef]

28. Alshaikh, I.M.H.; Bakar, B.H.A.; Alwesabi, E.A.H.; Zeyad, A.M.; Magbool, H.M. Finite element analysis and experimental validation of progressive collapse of reinforced rubberized concrete frame. Structures 2021, 33, 2361-2373. [CrossRef]

29. Mo, J.X.; Zeng, L.; Liu, Y.H.; Ma, L.L.; Liu, C.J.; Xiang, S.; Cheng, G.Y. Mechanical properties and damping capacity of polypropylene fiber reinforced concrete modified by rubber powder. Constr. Build. Mater. 2020, 242, 118111. [CrossRef]

30. Sambucci, M.; Marini, D.; Valente, M. Tire Recycled Rubber for More Eco-Sustainable Advanced Cementitious Aggregate. Recycling 2020, 5, 11. [CrossRef]

31. Chen, X.D.; Chen, C. Experimental Study on Damage Evolution Behavior of Self-Compacting Rubberized Concrete under Direct Tensile Fatigue Loading. KSCE J. Civ. Eng. 2020, 24, 3300-3308. [CrossRef]

32. Wu, C.; Li, W.B.; Shen, X.J. Study of the anti-penetration performance of concrete with different coarse aggregate content. Latin Am. J. Solids Struct. 2018, 15, 1-14. [CrossRef]

33. GB/T 17671-1999. Method of Testing Cements-Determination of Strength; The State Bureau of Quality and Technical Supervision of the People's Republic of China: Beijing, China, 1999.

34. Yang, G.; Chen, X.D.; Guo, S.S.; Xuan, W.H. Dynamic Mechanical Performance of Self-compacting Concrete Containing Crumb Rubber under High Strain Rates. KSCE J. Civ. Eng. 2019, 23, 3669-3681. [CrossRef]

35. Tan, G.J.; Zhu, D.Q.; Liang, C.Y.; Wu, C.L.; Zhu, Z.Q. Mechanical properties of polypropylene fiber reinforced engineering cementitious composites for bridges. J. Jilin Univ. (Eng. Technol. Ed.) 2020, 50, 1396-1402. [CrossRef]

36. JTG E30-2005. Test Methods of Cement and Concrete for Highway Engineering; Ministry of Transport of the People's Republic of China: Beijing, China, 2006.

37. JTG/T 3650-2020. Technical Specifications for Construction of Highway Bridges and Culverts; Ministry of Transport of the People's Republic of China: Beijing, China, 2020.

38. Nacif, G.L.; Panzera, T.H.; Strecker, K.; Christoforo, A.L.; Paine, K. Investigations on cementitious composites based on rubber particle waste additions. Mater. Res. 2013, 16, 259-268. [CrossRef]

39. Garcia, P.S.; Sousa, F.D.; Lima, J.A.D.; Cruz, S.A.; Scuracchio, C.H. Devulcanization of ground tire rubber: Physical and chemical changes after different microwave exposure times. Express Polym. Lett. 2015, 9, 1015-1026. [CrossRef]

40. Mohammadi, I.; Khabbaz, H.; Vessalas, K. Enhancing mechanical performance of rubberised concrete pavements with sodium hydroxide treatment. Mater. Struct. 2015, 49, 813-827. [CrossRef]

41. He, L.; Ma, Y.; Liu, Q.T.; Mu, Y.H. Surface modification of crumb rubber and its influence on the mechanical properties of rubber-cement concrete. Constr. Build. Mater. 2016, 120, 403-407. [CrossRef]

42. Zhang, S. Experimental Study on Mechanical Properties and Impermeability of Rubber Fiber Slag Modified Concrete. Master's Thesis, University of Science and Technology Liaoning, Anshan, China, 2020. [CrossRef]

43. Segre, N.; Joekes, I. Use of tire rubber particles as addition to cement paste. Cem. Concr. Res. 2000, 30, 1421-1425. [CrossRef]

44. Mohammed, B.S.; Adamu, M.; Shafiq, N. A review on the effect of crumb rubber on the properties of rubbercrete. International J. Civ. Eng. Technol. 2017, 8, 599-615.

45. Liu, F.; Wang, B.M.; Yuan, X.S.; Wang, Y.G.; Li, J. Experimental study on toughness of concrete containing scrap rubber. Concrete 2019, 3, 78-85. [CrossRef]

46. Rashad, A.M. A comprehensive overview about recycling rubber as fine aggregate replacement in traditional cementitious materials. Int. J. Sustain. Built Environ. 2016, 5, 46-82. [CrossRef] 
47. Li, J.; Lu, Z.H.; Zhang, Q.Y. Study on Stochastic Damage Constitutive Law for Concrete Material Subjected to Uniaxial Compressive Stress. J. Tongji Univ. 2003, 31, 505-509.

48. He, L.; Liu, Y.G.; Mou, Y.H. Rubber Modification and Its Influence on the Properties of Rubber Cement Matrix. Bull. Chin. Ceram. Soc. 2017, 36, 936-941. [CrossRef]

49. Chen, Z.W.; Hu, W.G. Effect of different rubber treatments on mechanical properties of modified cement concrete. Chin. Foreign Highw. 2016, 36, 258-261. [CrossRef]

50. Karger-Kocsis, J.; Mészáros, L.; Bárány, T. Ground tyre rubber (GTR) in thermoplastics, thermosets, and rubbers. J. Mater. Sci. 2012, 48, 1-38. [CrossRef] 